Scientific Journal of Hamadan Nursing \& Midwifery Faculty - ISSN 2008-2819

\title{
Factors Affecting the Duration of Weaning from Mechanical Ventilation Based on Burn Scale in the Intensive Care Units
}

\author{
Atefeh Ghanbari ${ }^{1}$, Aida Mohammad Ebrahimzadeh² ${ }^{*}$ Ezzat Paryad $^{3}$, Zahra Atrkar Roushan $^{4}$, \\ Mohammad Kazem Mohammadi ${ }^{5}$ \\ 1. Associate Professor, Department of Nursing (Medical-surgical), SDHRC, School of Nursing and Midwifery, \\ Guilan University of Medical Sciences, Rasht, Iran \\ 2. Master of Nursing (Critical Care), The Heart Hospital of Doctor Heshmat, Guilan University of Medical \\ Sciences, Rasht, Iran \\ 3. Instructor, Department of Nursing, SDHRC, School of Nursing and Midwifery, Guilan University of Medical \\ Sciences, Rasht, Iran \\ 4. Assistant Professor, Biostatistics, School of Medicine, Guilan University of Medical Sciences, Rasht, Iran \\ 5. Department of Nursing (Critical Care), Social Security Organization of Guilan Province, Rasoul Akram Hos- \\ pital, Rasht, Iran
}

\begin{tabular}{|c|c|}
\hline Article Info & Abstract \\
\hline $\begin{array}{lr}\text { Received: } & 2017 / 02 / 09 \\
\text { Accepted: } & 2017 / 06 / 06 \\
\text { Published Online } & 2017 / 07 / 17\end{array}$ & $\begin{array}{l}\text { Introduction: Mechanical ventilation has been one of the most common forms } \\
\text { of patients' medical treatment in intensive care unit and several factors affect the } \\
\text { preparation of patients for weaning the mechanical ventilation. This study aimed at } \\
\text { determining factors that have an impact on the duration of mechanical ventilation } \\
\text { weaning. }\end{array}$ \\
\hline
\end{tabular}

DOI: $10.30699 /$ sjhnmf.26.1.33

Original Article

Use your device to scan and read the article online

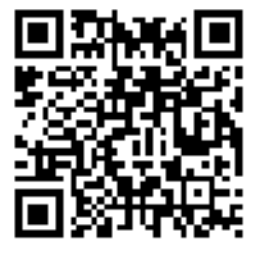

Methods: In this sectional -analytical study, 65 ICU patients who required mechanical ventilation for more than 72 hours were selected by convenience sampling. Patients with Burns Wean Assessment Program tools were studied in three shifts. Patient's age, sex, the reason for connecting them to mechanical ventilation, the level of consciousness based on the Ramsay sedation scale, and duration of mechanical ventilation were recorded before weaning. The results were analyze through descriptive statistics and an independent t-test using SPSS 22.

Results: The average duration of weaning the mechanical ventilation using Burns Wean Assessment Program was 111/75 33/46. The results, in addition, showed that confounding factors of sex $(P=0 / 03)$ and Ramsay sedation scale score $(P=0 / 0001)$ had a significant effect on the duration of mechanical ventilation, but age $(P=0 / 2)$ and the reason for connecting them to mechanical ventilation $(P=0 / 319)$ had no significant effect on the duration of mechanical ventilation.

Conclusion: To wean the mechanical ventilation from the patients, some factors such as age and the level of consciousness - also in applying measurement devises for these variables- should be considered.

Keywords: Mechanical Ventilator Weaning, Intensive Care Unit, Mechanical Ventilation, Burns scale

Copyright $($ C 2018, Sci J Hamadan Nurs Midwifery Fac. This is an open-access article distributed under the terms of the Creative Commons Attribution-noncommercial 4.0 International License which permits copy and redistribute the material just in noncommercial usages, provided the original work is properly cited.

How to Cite This Article:

Ghanbari A, Mohammad Ebrahimzadeh A, Paryad E, Atrkarroshan Z, Mohammadi M. Factors Affecting the Duration of Weaning from Mechanical Ventilation Based on Burn Scale in the Intensive Care Units. Sci J Hamadan Nurs Midwifery Fac. 2018; 26 (1): 33-39 
مجله علمى دانشكده يرستارى و مامايى همدان - شايا الكترونيك: 19

مقاله يثروهشى

\section{بررسى طول مدت جداسازى از دستگًاه تهويةٌ مكانيكى براساس مقياس برن و عوامل مرتبط با

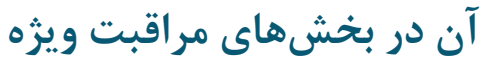

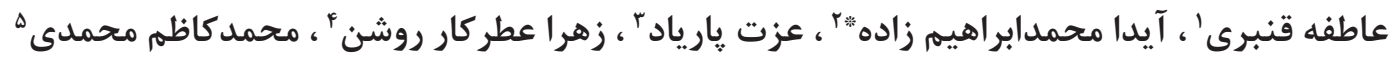

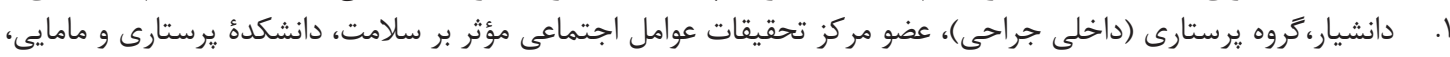

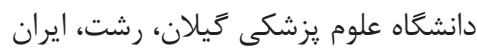

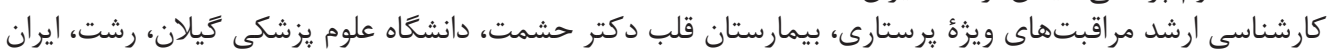

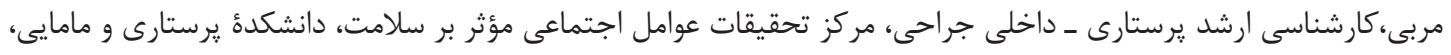

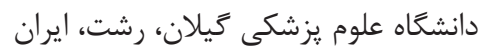

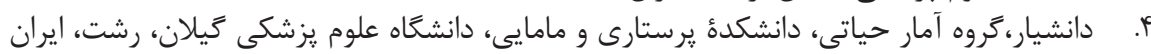

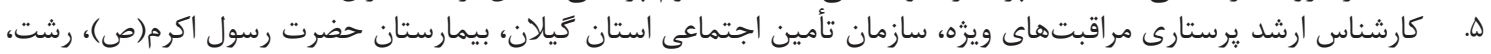

ايران

جكيده

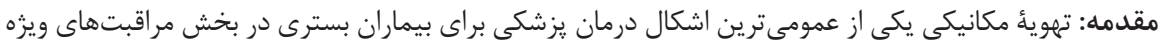

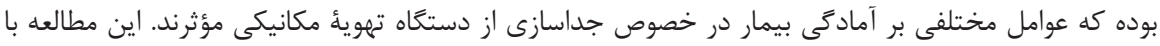

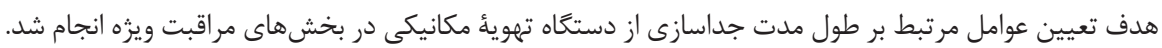

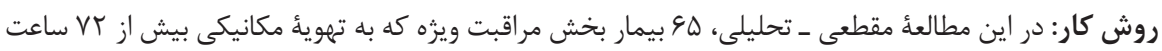

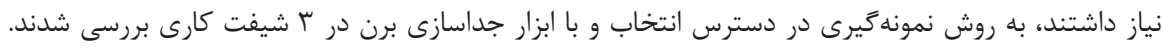

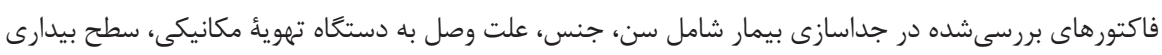

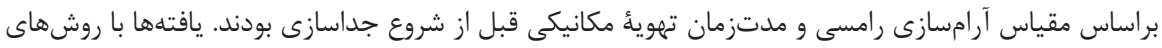

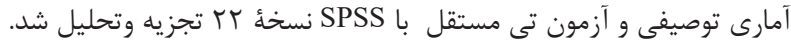

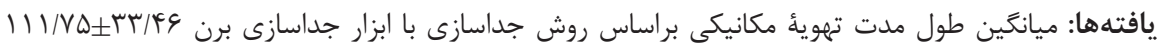

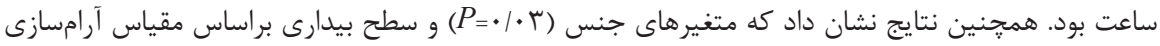

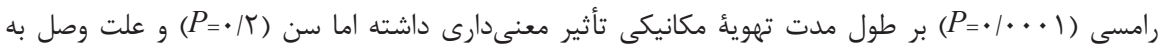

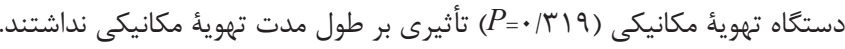

نتيجهَّيرى: براى بررسى آمادگى بيمار در خصوص جداسازى از دستخاه تهويأ مكانيكى بايد به عوامل متعددى إنى

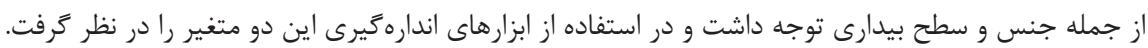

| - اطلاعات مقاله

تاريخ وصول: ت ت ت تاريخ يذيرش:

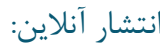

نويسندةٔمسئول: آيدا محمدابر اهيم زاده كارشناسى ارشد مراقبت هاى ويزٔه يرستارى، بيمارستان قلب دكتر حشمت، دانشگاه علوم زيزشكى بيماني كيلان، رشت، ايران يست الكترونيك:

Aidame64@Gmail.com وازههاى كليدى: جداسازى از تهوئُ مكانيكى، بخش مراقبت ويزه، تهوئه مكانيكى، ابزار برن

افزايش نياز به آرامبخشهاو آنارضايتى ميان پرسنل، بيماران

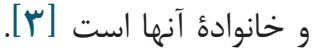

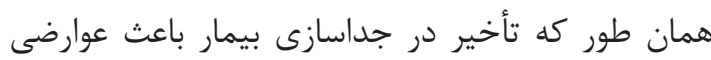

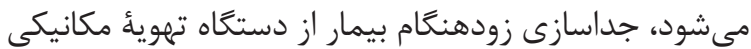

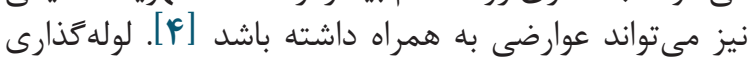

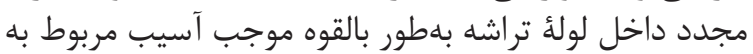

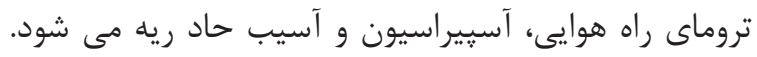

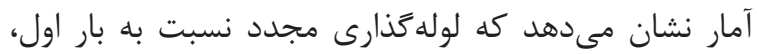

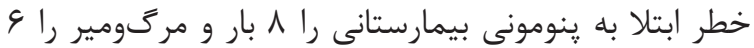

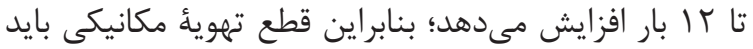

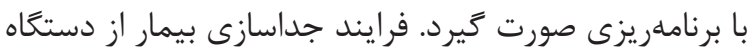

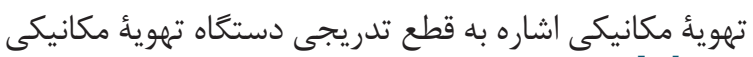

دارد [ب].

تأثير تصميمگيرىهاى صحيح و باموقع زيرستاران در

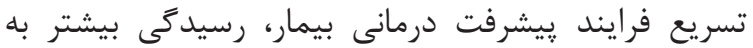

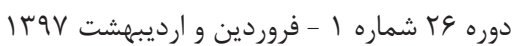

مقدمه

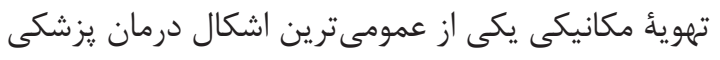

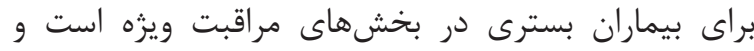

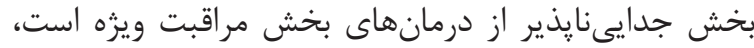

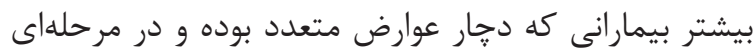

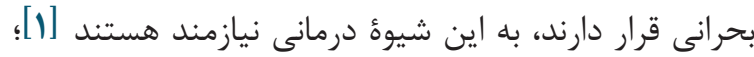

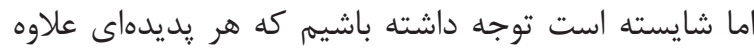

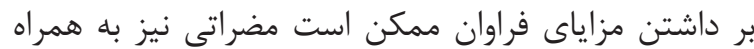

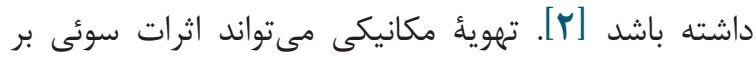
دستخاههاى قلب و عروق، تنفس، كوارش و اسكلتى ـ عضلانى

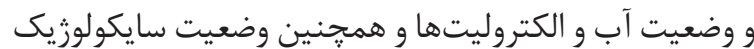

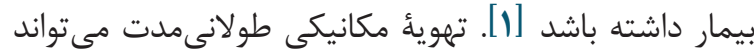

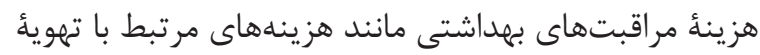

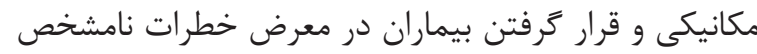

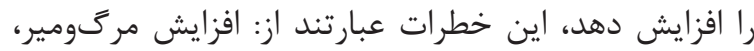

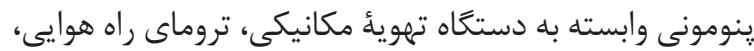

$$
\text { مجله علمى دانشكده يرستارى و مامايى همدان }
$$




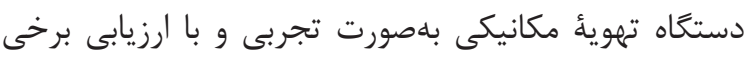

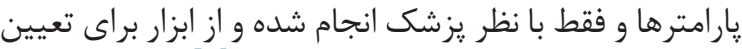

سنجش آمادگى بيمار استفاده نمىشود [1/.

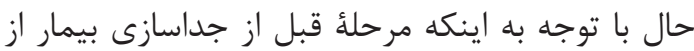

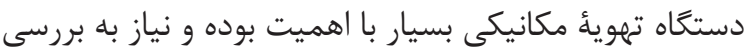

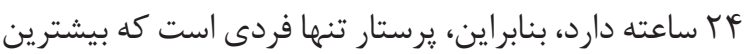

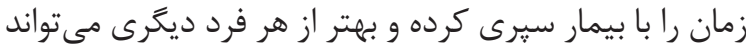

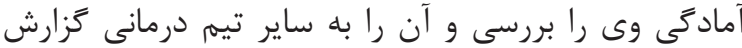

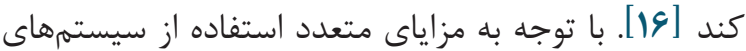

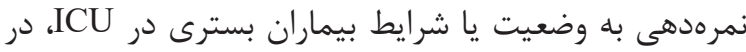

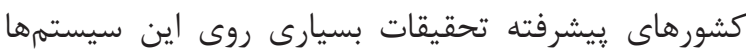

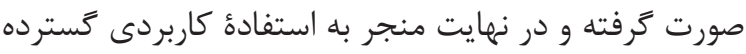

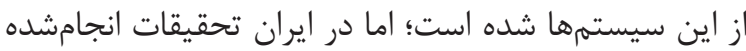

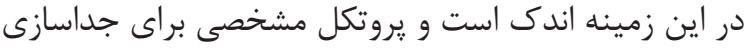

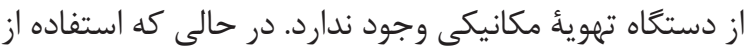

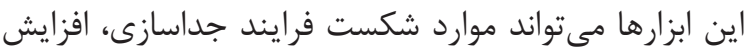

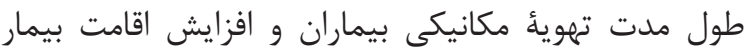

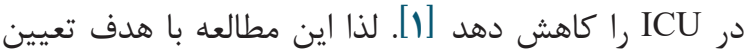

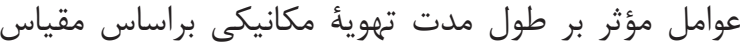

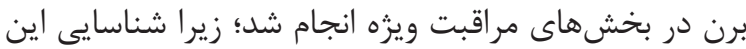

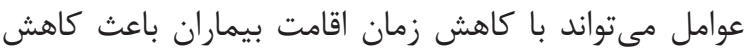

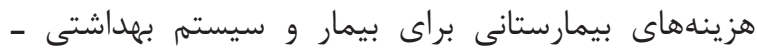

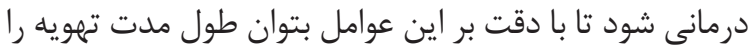

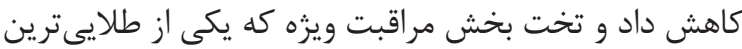

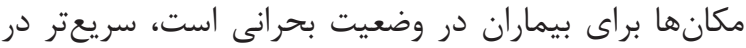
اختيار اين بيماران قرار كيرد.

\section{روش كار}

مطالعه حاضر مقطعى از نوع تحليلى و تك كروهانه است.

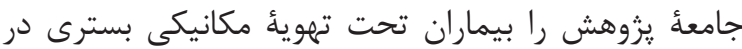

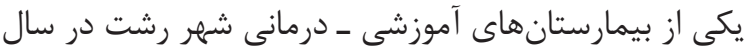

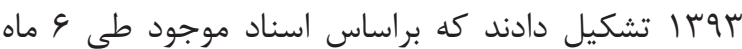

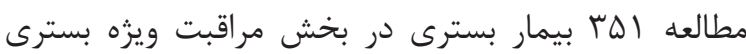

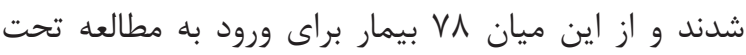

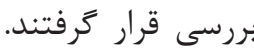

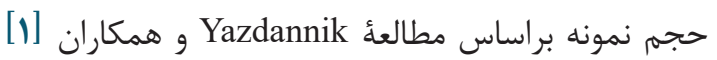

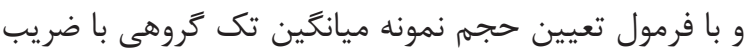
اطمينان

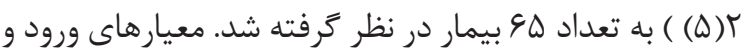

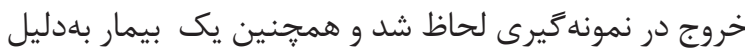

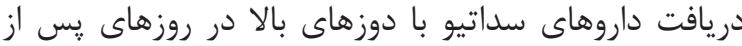

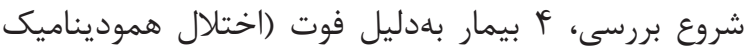

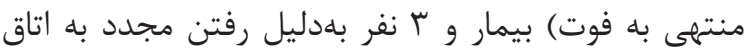

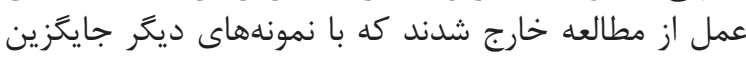

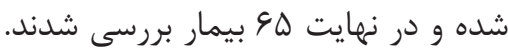

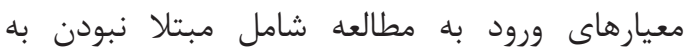

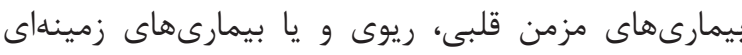
ديخر (مانند بيمارىهاى كليوى يا متابوليكى)، نداشتن سابقئ
آنان و كاهش هزينههاى درمان بر كسى يوشيده نيست [ه]].

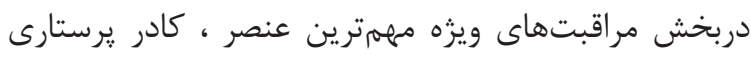

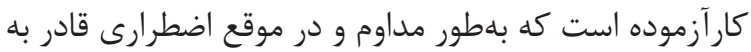

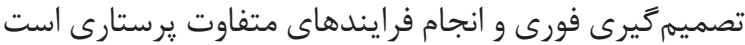

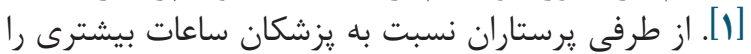

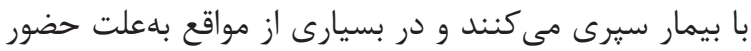

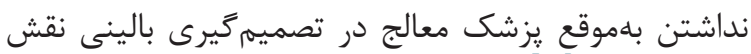

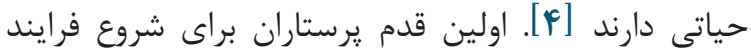

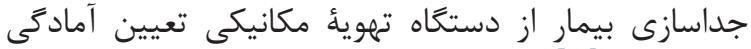

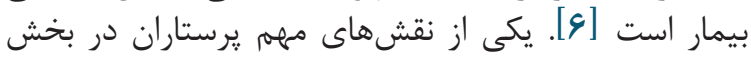

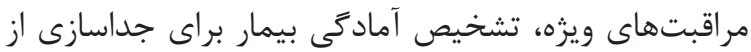

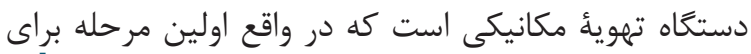

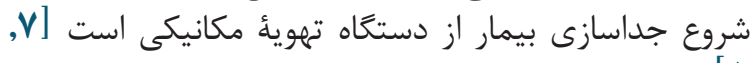

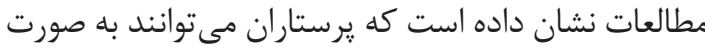

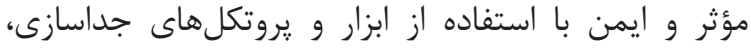

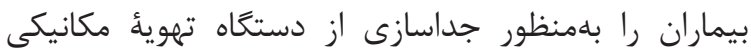

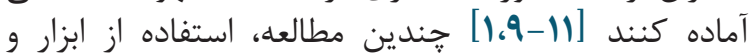

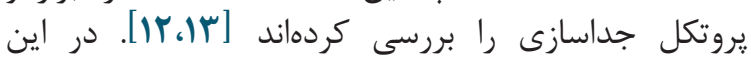

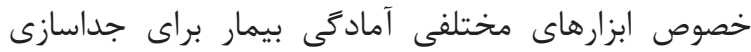

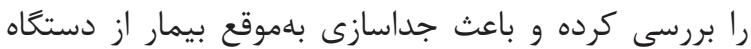

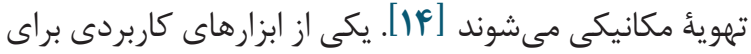

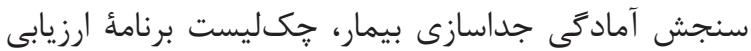

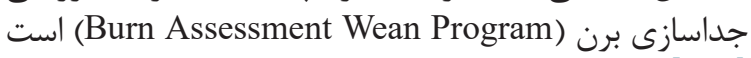

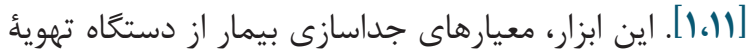

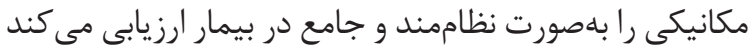

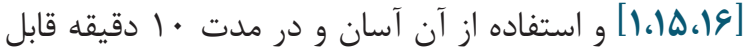

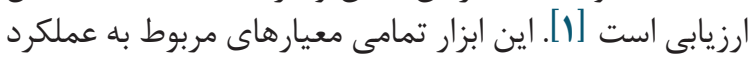

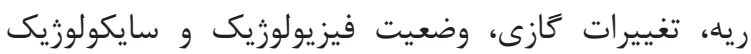

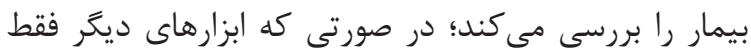

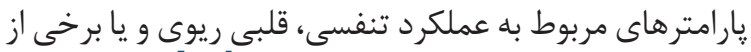

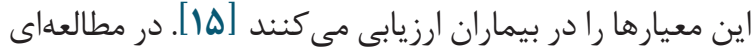

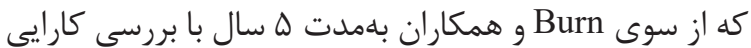

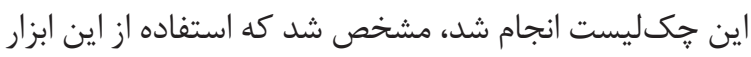

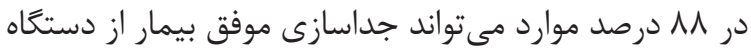

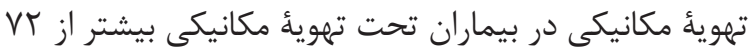

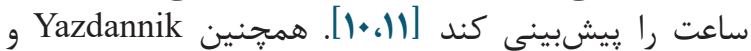

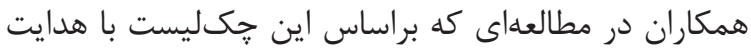

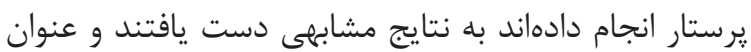

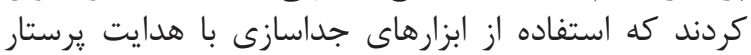

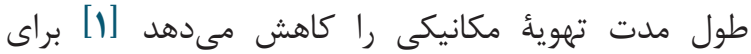

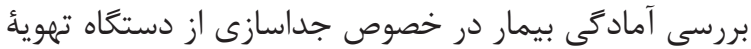

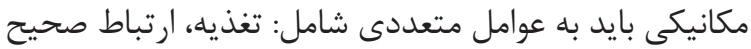

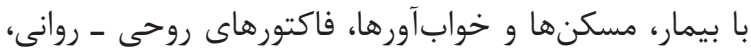

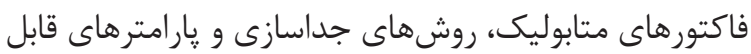

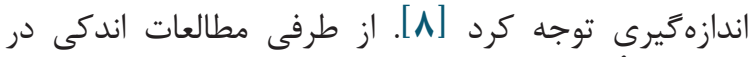

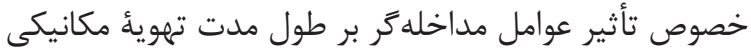

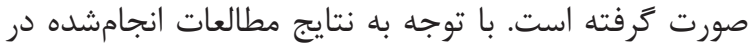

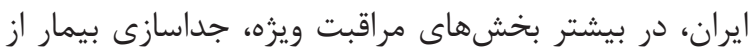


دانشعاه و يس از حصول اطمينان از داشتن شرايط ورود

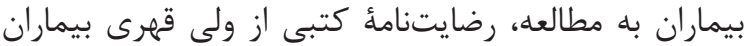

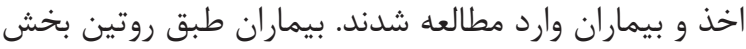

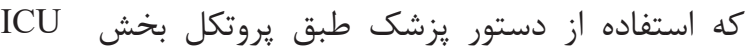

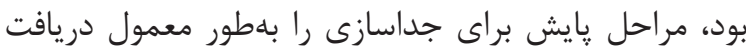

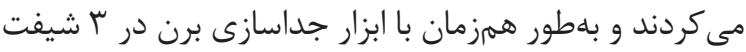

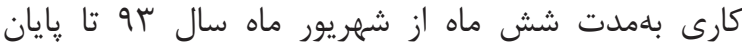

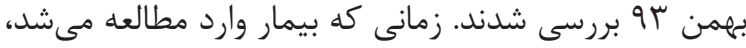

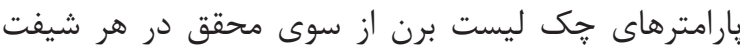

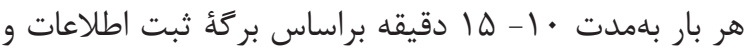

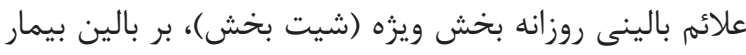

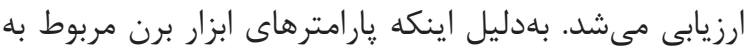

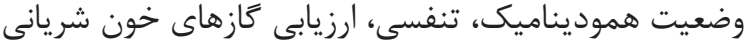

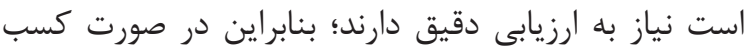

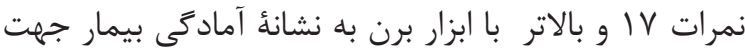

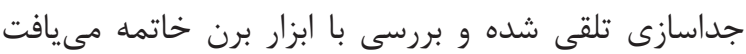

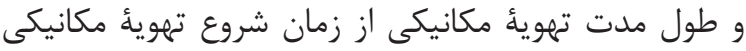

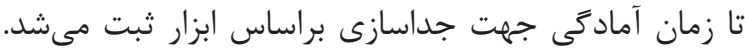

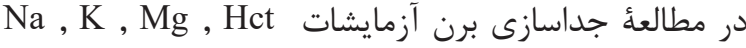
, كه جزء پارامترهاى سنجش آمادكى , Alb, Ca , P، ABG

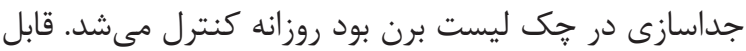

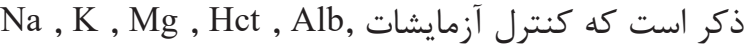
Ca , P, ABG

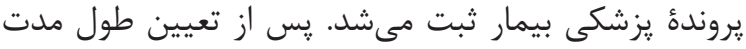

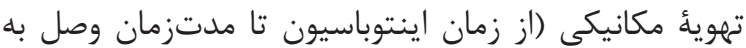

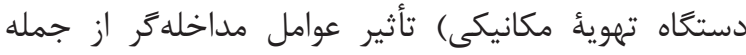

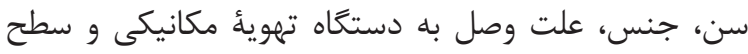
آرامسازى براساس ابزار رامسى بررسى شد.

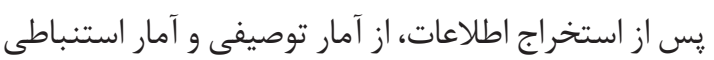

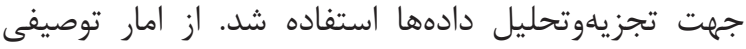

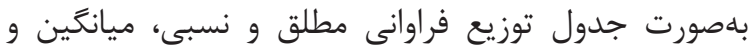

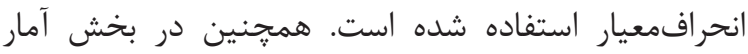

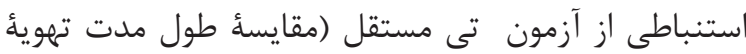

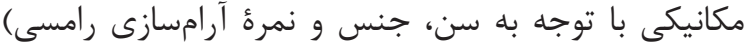

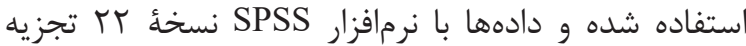

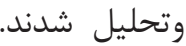

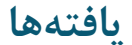

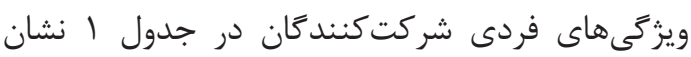

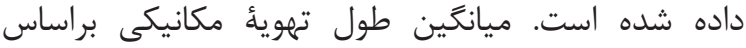

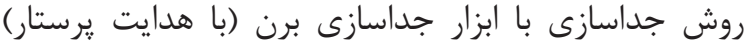

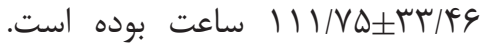

براساس جدول شماره يك، طول تهويةٔ مكانيكى در مردان

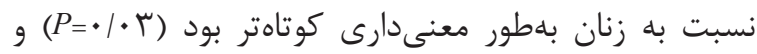

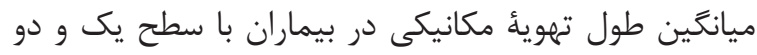

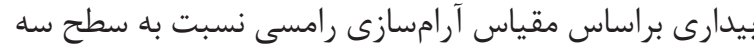

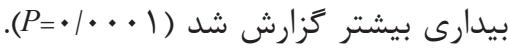

بيمارى نروماسكولار (عصبى عضلانى)، وضعيت هوشيارى

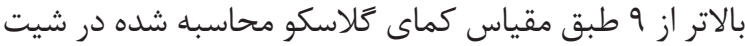
و قرار نداشتن بيمار در مرحلة جداسازى بود. ICU همجنين بيماران در صورت فوت، انتقال به مراكز درمانى

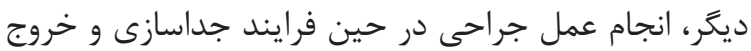

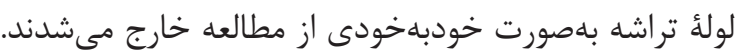

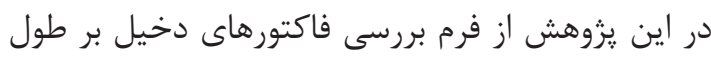

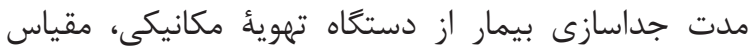

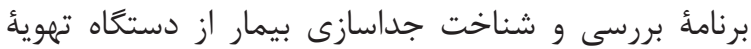

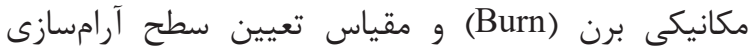

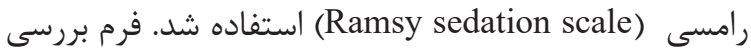
فاكتورهاى دخيل بر طول مدت جداسازى بيمار از دستغاه

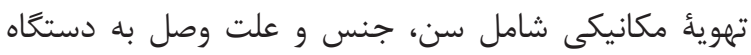

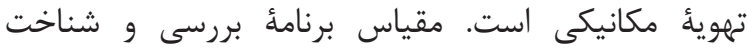

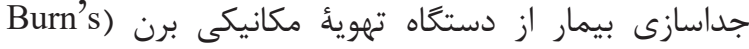
assessment wean program

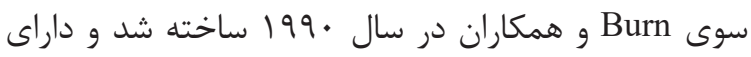

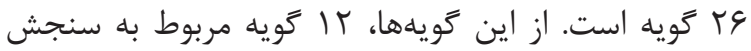

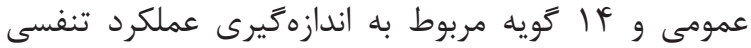

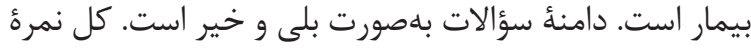

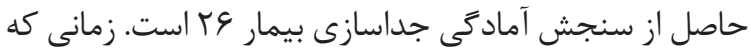

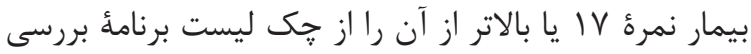

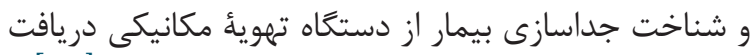

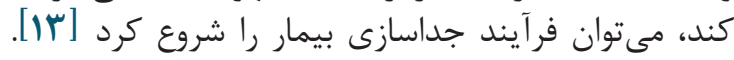
جكليست برنامهٔ جداسازى برن، يك קكاليست استاندارد

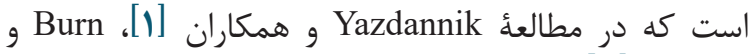
همكاران [9] استفاده شده است.

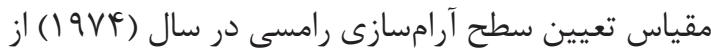

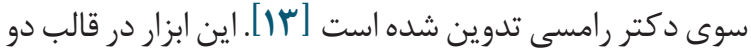

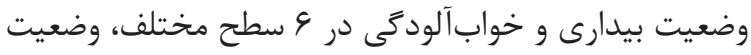

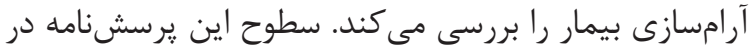

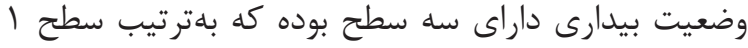

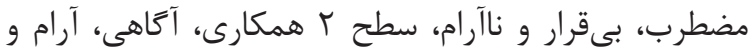

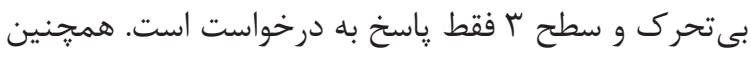

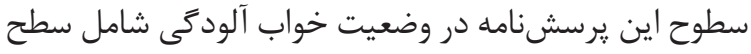

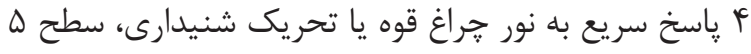

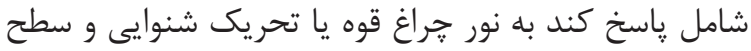

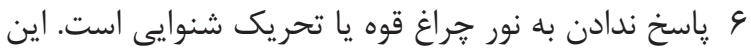

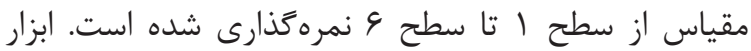

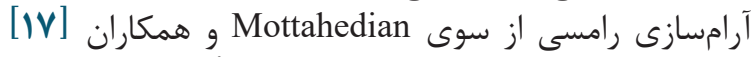
روايى و يايايى آن بررسى شده و يايايى آن تأييد شد ( IVVD.

روش كردآورى دادهها با استفاده از مشاهدة فاكتورها،

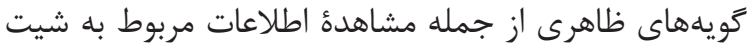

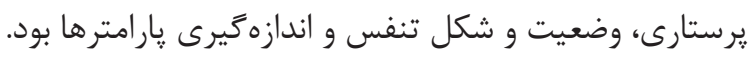

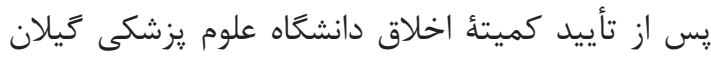

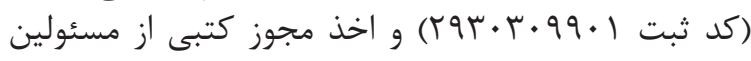


جدول ا. بررسى تأثير سن، جنس، تحصيلات، علت وصل و نمرة آرامسازى رامسى بر مدتزمان جداسازى براساس ابزار جداسازى برن

\begin{tabular}{|c|c|c|c|c|}
\hline$" P$ & 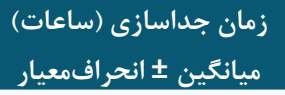 & تعداد (درصد) & & 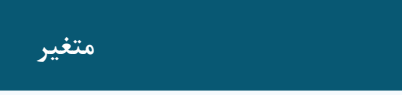 \\
\hline \multirow{2}{*}{$\cdot / \cdot r$} & $1 \cdot V / \cdot q \pm r V / \wedge \Delta$ & $(\vee \& / 9) \Delta \cdot$ & 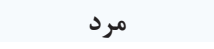 & \multirow{2}{*}{ جنس } \\
\hline & $\mid r V / T \cdot \pm F \Delta / F \varphi$ & Q & 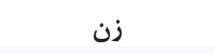 & \\
\hline \multirow{2}{*}{$\cdot / 419$} & $\| F / Y F \pm r q / \wedge D$ & $(\varepsilon+/ 1) \& 1$ & ت ت تروما & \multirow{2}{*}{ علت وصل به دستخًاه تهويئ مكانيكى } \\
\hline & $\mid r T / G T \pm \Delta F / I V$ & $(r / 9) Y F$ & غير تروما & \\
\hline \multirow{2}{*}{$.1 \cdots 1$} & $\mid r K / Q \Lambda \pm T Y / Y T$ & $(\kappa T / 1)\lceil\Lambda$ & سطح او ז بيدارى & \multirow{2}{*}{ نمرء آرامسازى Ramsay } \\
\hline & $91 / 9 \vee \pm r \cdot / V r$ & $(\Delta q / q) r V$ & سطح \ بيدارى & \\
\hline \multirow{2}{*}{$\cdot / 4$} & $1.9 / 9 \Delta \pm r q / \Delta r$ & $(\Delta \Delta / \Psi) r^{\prime}$ & زير •f سال & \multirow{2}{*}{ 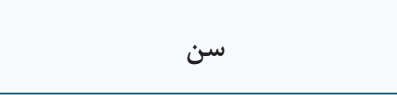 } \\
\hline & $11 V / V \cdot \pm r V / 49$ & $(Y</ \varepsilon) Y q$ & بالاى •f سال & \\
\hline
\end{tabular}

Independent T-Test *

Epstein

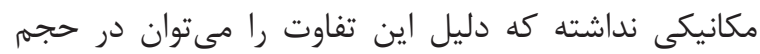

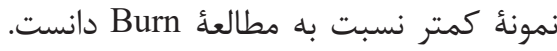

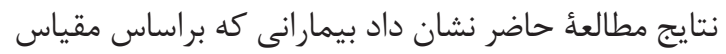

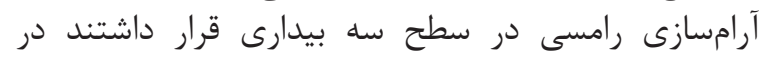

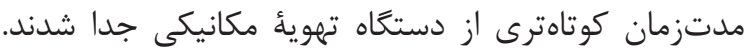

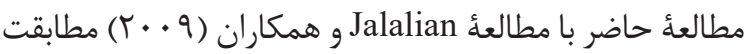

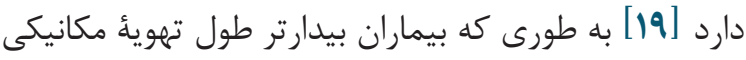

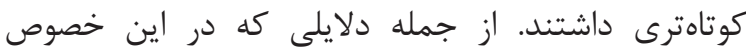

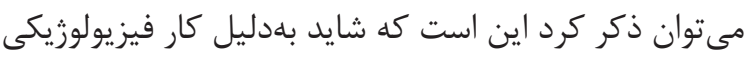

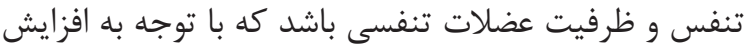

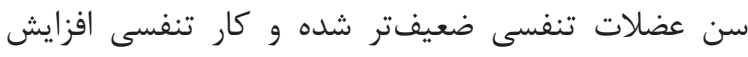

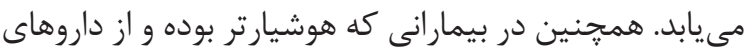

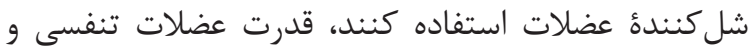

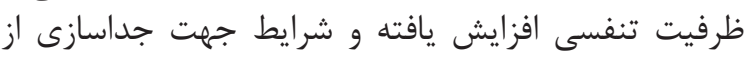
تهويئ مكانيكى تسهيلتر مىشود.

\section{نتيجهل نيرى}

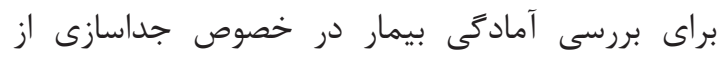

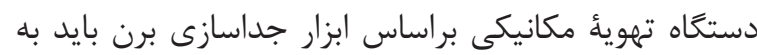

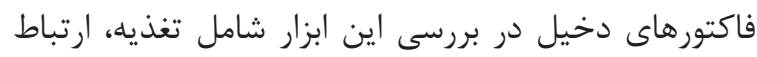

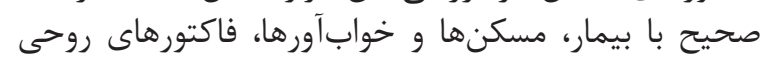

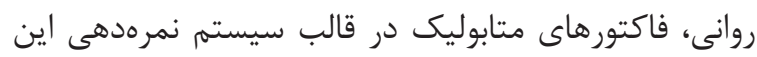

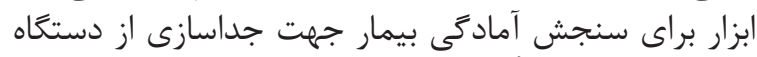

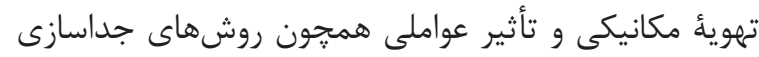

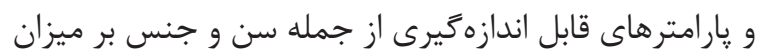

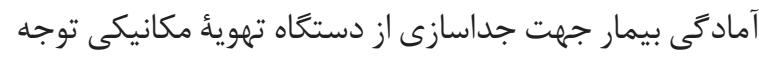

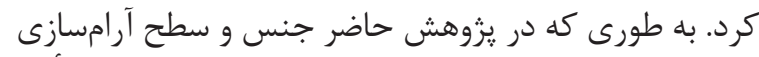

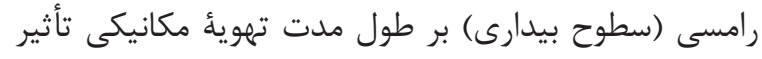

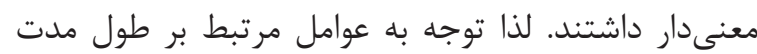

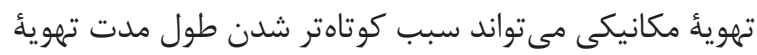
مكانيكى و در نتيجه كاهش عوارض مارن احتمالى شود.

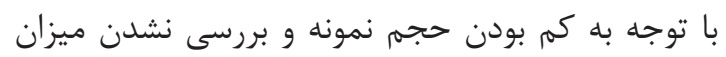

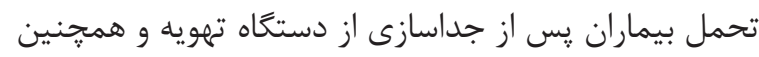

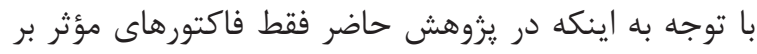

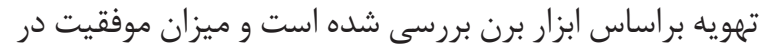

نتايج مطالعهُ حاضر نشان داد كه مداخله كَهايى مثل

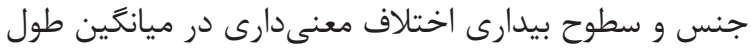

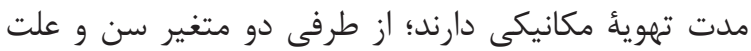

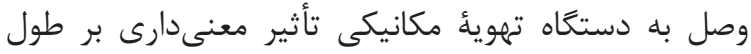
مدت تهويأ مكانيكى نداشتند.

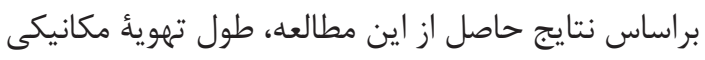

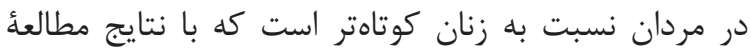
Burn

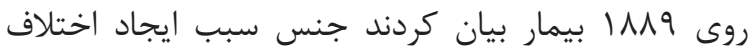

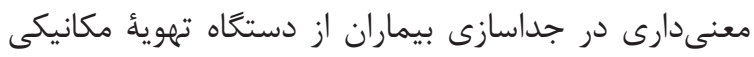

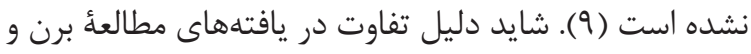

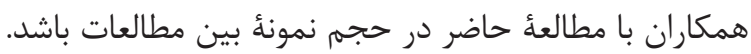
Carson

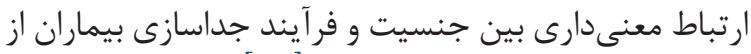

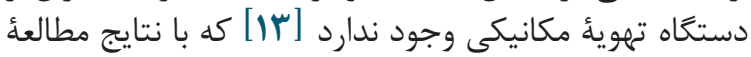

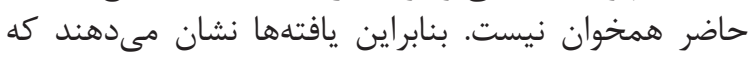

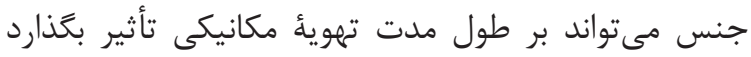

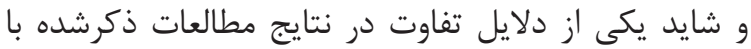
مطالعُ حاضر در حجم نمونه بين مطالعات بات باشد.

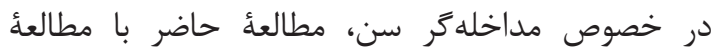
Epstein

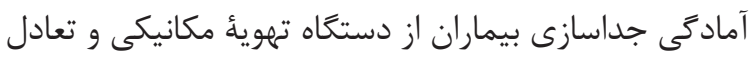

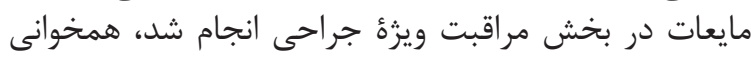

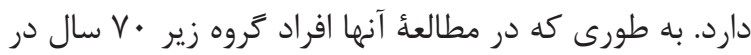

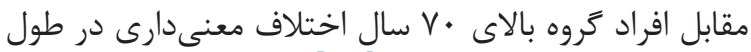

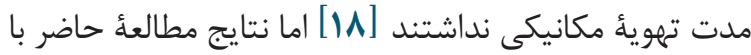

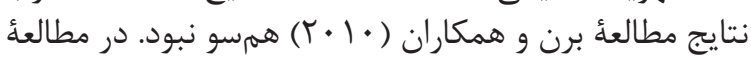

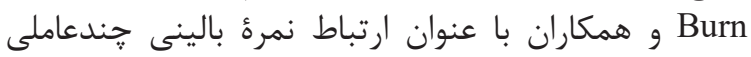

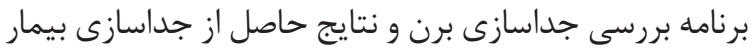

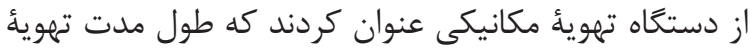

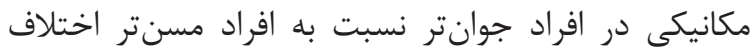

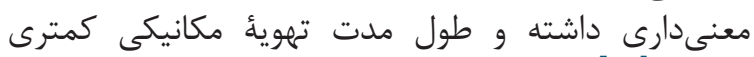

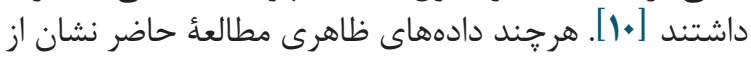

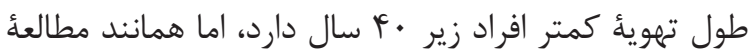


جداسازى برن (با هدايت يرستار) و روش روتين در بيماران

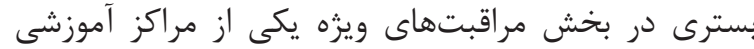

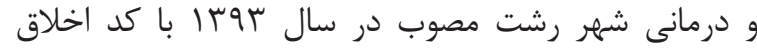

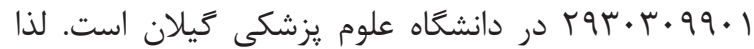

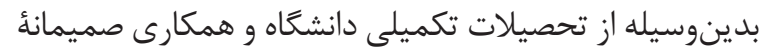

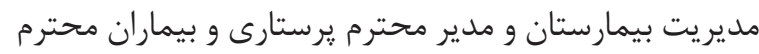

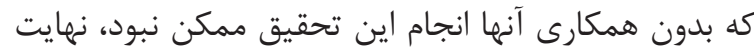

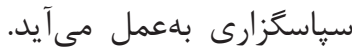
تضاد منافع در اين مطالعه تضاد منافع وجود ندارد.
جداسازى بررسى نشده، ييشنهاد مى شود يزوهشى با همين

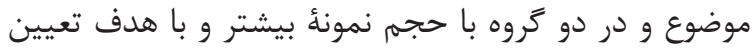

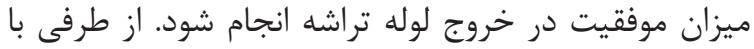

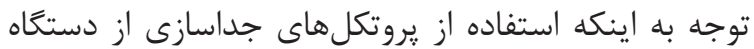

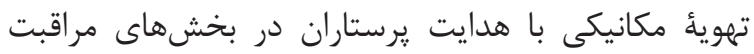

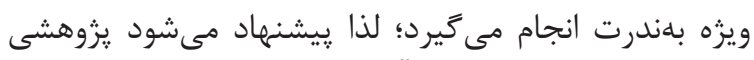

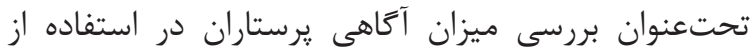
يروتكلهاى جداسازى و روش يرهاى آن، انجام يذيرد.

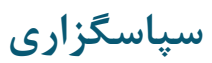

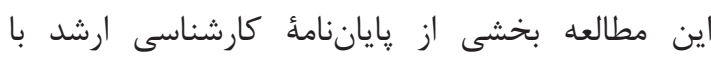

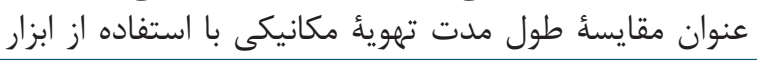

\section{References}

1. Yazdannik AR, Salmani F, Irajpour AR, Abasi S. Effect of the Nurse-directed Weaning Readiness Assessment on the Duration of Mechanical Ventilation: A Randomized Clinical Trial. J Qom Univ Med Sci. 2013;7(4):89-94.

2. Radhakrishnan M, Ghosh I, Dash HH. Evaluation of an indigenous ventilator for weaning in intensive care unit. J Anaesthesiol Clin Pharmacol. 2007;23(3):297-302.

3. McLean SE, Jensen LA, Schroeder DG, Gibney NRT, Skjodt NM. Improving adherence to a mechanical ventilation weaning protocol for critically ill adults: outcomes after an implementation program. Am J Crit Care. 2006;15(3):299-309. PMid: 16632772

4. Ely EW, Meade MO, Haponik EF, Kollef MH, Cook DJ, Guyatt GH, et al. Mechanical Ventilator Weaning Protocols Driven by Nonphysician Health-Care Professionals Evidence-Based Clinical Practice Guidelines. Chest Journal. 2001;120(6_suppl):454S-63S.

5. Mokhtari M, Saadat Niaki A, Rashidi MF. Study of the mortality rate in patients receiving artificial respiration in the intensive care unit of a hospital in Tehran during 2002-2003. J Iran Society Anaesthesiol Intensive Care 2004;45(2):26-34.

6. Kaplow R. Critical care nursing: synergy for optimal outcomes. Massachusetts: Jones \& Bartlett Publishers; 2007.

7. Monaco F, Drummond G, Ramsay P, Servillo G, Walsh T. Do simple ventilation and gas exchange measurements predict early successful weaning from respiratory support in unselected general intensive care patients? $\mathrm{Br} \mathrm{J}$ Anaesth. 2010;105(3):326-33. https://doi.org/10.1093/bja/ aeq184 PMid:20656695

8. Soran A, Chelluri L, Lee KKW, Tisherman SA. Outcome and quality of life of patients with acute pancreatitis requiring intensive care. J Surg Res. 2000;91(1):89-94. https://doi.org/10.1006/ jsre.2000.5925 PMid: 10816356

9. Chaiwat O, Sarima N, Niyompanitpattana K. Protocol-directed vs. physician-directed weaning from ventilator in intra-abdominal surgical patients. J Med Assoc Thai. 2010;93(8):930-6.

10. Burns SM, Fisher C, Earven Tribble SS, Lewis R, Merrel P, Conaway MR, et al. Multifactor clinical score and outcome of mechanical ventilation weaning trials: Burns Wean Assessment Program. Am J Crit Care. 2010;19(5):431-9. https:// doi.org/10.4037/ajcc2010273 PMid:20810418

11. Burns SM, Fisher C, Tribble SE, Lewis R, Merrel $\mathrm{P}$, Conaway MR, et al. The relationship of 26 clinical factors to weaning outcome. Am J Crit Care. 2012;21(1):52-8. https://doi.org/10.4037/ ajcc2012425 PMid:22210700

12. Khamiees $M$, Raju $P$, DeGirolamo A, Amoateng-Adjepong Y, Manthous CA. Predictors of extubation outcome in patients who have successfully completed a spontaneous breathing trial. Chest. 2001;120(4):1262-70. https://doi. org/10.1378/chest.120.4.1262 PMid: 11591570

13. Carson SS, Bach PB, Brzozowski L, Leff A. Outcomes after long-term acute care: an analysis of 133 mechanically ventilated patients. Am J Respir Crit Care Med. 1999;159(5):1568-73. https://doi.org/10.1164/ajrccm.159.5.9809002 PMid: 10228128

14. Blackwood B, Alderdice F, Burns K, Cardwell C, Lavery G, O’Halloran P. Use of weaning protocols for reducing duration of mechanical ventilation in critically ill adult patients: Cochrane systematic review and meta-analysis. BMJ: British Medical Journal. 2011;342:c7237. https:// doi.org/10.1136/bmj.c7237 PMid:21233157 PMCid:PMC3020589

15. Knebel AR, Shekleton ME, Burns S, Clochesy JM, Hanneman SK, Ingersoll GL. Weaning from mechanical ventilation: concept development. Am J Crit Care. 1994;3(6):416-20. 
آيدا محمدابراهيم زاده و همكاران. 9

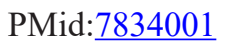

16. Plang-Wan LR. The Effects Of Providing Information And Instilling Reassurance On Uncertainty In Weaning From Mechanical Ventilation: Faculty of Graduate studies. Thailand: Mahidol University. Masters thesis of nursing science (adult nursing); 2004.

17. Mottahedian Tabrizi E, Tadrisi SD, Mohammad Yari A, Abdi A, Mirhashemi S. Validity and reliability of Ramsy sedation scale in adult patients hospitalized in critical care units. Critical Care Nursing. 2009;3(1):39-44.

18. Epstein CD, Peerless JR. Weaning readiness and fluid balance in older critically ill surgical patients. Am J Crit Care. 2006;15(1):54-64.

19. Jalalian H, Aslani J, Panahi Y. Factors affecting the duration of mechanical ventilation device isolation of patients in intensive care units. Kowsar Medical Journal. 2009;14(3):163-8. 